\title{
Rheumatoid Arthritis and Periodontal Disease: A Rheumatologist's Perspective
}

\author{
Elliot D. Rosenstein • Laura J. Kushner • Neil Kramer
}

Published online: 28 December 2014

(C) Springer International Publishing AG 2014

\begin{abstract}
Despite advances in our understanding of the inflammatory events that underlie rheumatoid arthritis (RA), which have led to targeted therapies that more effectively control the condition, the etiology of RA is not fully understood. With the discovery that serum antibodies to citrullinated peptides (ACPA) are highly specific for RA and that Porphyromonas gingivalis, the major pathogen responsible for periodontitis (PD), contains the enzyme responsible for the citrullination of peptides, a plausible explanation for observations of increased incidence and severity of PD in RA patients and an appreciation of pathogenic similarities between the two conditions has emerged. Studies of the effect of RA treatment on the severity of PD have been limited and conflicting, especially with respect to anti-TNF agents, but indicate the potential for IL- 6 as a therapeutic target for both conditions. PD treatment appears to improve clinical and laboratory evidence of RA disease activity, and the response of RA to anti-TNF therapy is abrogated by the presence of PD.
\end{abstract}

This article is part of the Topical Collection on Systemic Diseases

E. D. Rosenstein $(\triangle) \cdot$ N. Kramer

Institute for Rheumatic and Autoimmune Diseases, Overlook

Medical Center, 33 Overlook Road, Summit, NJ 07901, USA

e-mail: Elliot.rosenstein@atlantichealth.org

E. D. Rosenstein $\cdot$ N. Kramer

Division of Rheumatology, Icahn School of Medicine at Mount

Sinai, New York, NY, USA

E. D. Rosenstein • L. J. Kushner • N. Kramer

Sjögren's Syndrome Program, Overlook Medical Center, Summit, NJ, USA

L. J. Kushner

Dry Mouth Clinic, Department of Dentistry, Overlook Medical

Center, Summit, NJ, USA
Thus, evaluation and treatment of PD can be recommended for all RA patients.

Keywords Rheumatoid arthritis $\cdot$ Rheumatoid factor . Periodontitis · Citrullination $\cdot$ ACPA $\cdot$ Porphyromonas gingivalis $\cdot$ Pathogenesis

\section{Introduction}

Rheumatoid arthritis (RA) and periodontal disease (PD) are common chronic inflammatory diseases, with pathophysiological similarities that have been appreciated for over 30 years [1]. In the past decade, major advances in our understanding of common risk factors and underlying biochemical and immunological processes have supported a direct, possibly causal association between the two conditions. To understand the potential connection between the two conditions, some basic knowledge of RA is necessary.

RA is a systemic autoimmune disease characterized by chronic joint inflammation, progressive destruction of articular cartilage, and bone erosion, ultimately leading to loss of joint integrity. Although RA manifests primarily as articular disease, periarticular manifestations such as bursitis, tenosynovitis, and carpal tunnel syndrome may also be seen. Beyond joint involvement, RA can cause constitutional symptoms such as malaise, fatigue, anemia, and thrombocytosis, all of which represent systemic manifestations of the condition. In addition, it has effects on multiple organ systems (e.g., keratoconjunctivitis sicca, xerostomia [Sjögren's syndrome], lymphadenopathy, pleuropericarditis, splenomegaly, peripheral neuropathy, and vasculitis) [2].

RA is the most common inflammatory arthritis, affecting approximately $1 \%$ of the adult population worldwide. Its peak onset is usually between the ages of 30 and 50 years, but it can occur at virtually any age, including in childhood. The 
prevalence in the United States is estimated at 2.1 million (25 new cases per 100,000 persons for men and 54 per 100,000 persons for women annually), with women two to three times more commonly affected than men [2].

RA is responsible for a high level of functional impairment and work disability, and it contributes to a reduction in quality of life due to factors such as pain, fatigue, depression, anxiety, separation and divorce, job change, and dependence on others [3]. The life expectancy of patients with RA may be reduced by as much as 5 to 15 years $[4,5]$. Cardiovascular disease is generally considered to be the leading cause of mortality in patients with RA, accounting for about half of all deaths [5].

RA behaves differently in different individuals, and should really be considered a syndrome with common manifestations. The final common pathway includes persistent synovial inflammation and associated cartilage and bone damage, but different disease subsets can be separated by clinical phenotype (erosion or extra-articular manifestations), particularly by the presence or absence of "specific" autoantibodies (rheumatoid factor $[\mathrm{RF}]$ and antibodies to citrullinated peptides [ACPA]) [2].

\section{Who Gets Rheumatoid Arthritis, and Why?}

Despite impressive strides in our understanding of the inflammatory events that underlie RA, and the therapeutic interventions that much more effectively control the condition, the etiology of RA is not fully understood. As has been contemplated for most autoimmune diseases, both environmental influences and genetic factors contribute to the development of the condition. More than 100 genetic loci have been linked with RA susceptibility [6]. The most important genetic risk, seen in approximately $80 \%$ of white patients with RA, is the conserved genetic sequence ("shared epitope") of the amino acid sequence at positions $70-74$ of the DR $\beta 1$ chain, located in the HLA-D region of chromosome 6 [7], although this is also found in $20 \%$ of the general population [8]. Genomewide association studies, however, can only explain about one-quarter of the disease variance [9]. Studies in monozygotic twins revealed a concordance rate of only up to 15$30 \%$, suggesting that environmental or perhaps epigenetic factors, or both, are required for the development of clinically evident RA [9].

Some ethnic groups, particularly some Native American populations (Pima, Tlingit, Yakima, and Chippewa) [10-12], have a strikingly high prevalence of the disease, leading to the speculation that RA is a disease of the New World that was "transmitted" to European and other populations after the period of European colonization [13, 14]. This conclusion is supported by paleopathology demonstrating evidence of RA in North American native groups dating back thousands of years, but only in Europe since the 1780s. Weissmann has suggested that this corresponds with the availability of sugar and molasses from the West Indies and the resultant higher incidence of dental caries and PD among the European bourgeoisie [14]. Interestingly, the North American native populations with a high prevalence of RA have a similarly high prevalence of the associated "shared epitope" [15], and have been reported to have a particularly high incidence of PD $[16,17]$.

\section{Rheumatoid Arthritis and Periodontal Disease: Rheumatoid Factor and ACPA, via P. Gingivalis}

The concept that intraoral infection is implicated in RA pathogenesis is not original. In the early days of the 20th century, the "oral sepsis" hypothesis was proposed, implicating apical infections of the teeth as the cause of RA [18]. This led to the use of dental extraction as a therapeutic option, which continued for at least four decades until it was eventually deemed ineffective.

In the 1980s, the concept that the inflammatory mechanisms underlying RA and PD shared common features was first introduced by Snyderman and McCarty [1], noting that both conditions involved self-sustaining inflammation in a fluid-filled compartment, in which the inflammatory cells and other mediators eventually lead to erosion of adjacent bone. Studies have identified inflammatory mediators, including tumor necrosis factor (TNF)- $\alpha$, IL-1, IL-6, prostaglandin $\mathrm{E} 2$, reactive oxygen species, and matrix metalloproteinases, that can lead to the bone destruction shared by the two diseases $[14,19]$. The similarities between the two conditions were further emphasized by Greenwald and Kirkwood, who suggested that proof-of-concept studies could be performed in patients with PD in order to validate therapeutic approaches prior to embarking on clinical trials in patients with RA [20].

In has long been known that patients with active RA demonstrate significantly increased frequency and severity of periodontal diseases as well as tooth and alveolar bone loss, with several recent studies substantiating the presence of PD in patients with RA early in the course of disease [21-23, 24*•]. The early development of RA argues for either a causal relationship between the two conditions or a shared etiopathogenesis, or both. A recent study linked the presence of alveolar bone loss with diagnosis of RA compared with osteoarthritis controls, and the magnitude of alveolar bone loss with RA disease activity, including autoantibody levels $[25 \bullet \bullet$.

RF is the hallmark autoantibody linked with RA. These antibodies, typically IgM or IgA targeting the Fc portion of $\mathrm{IgG}$, have long been identified as predictors of more severe disease and extra-articular manifestations, but their pathogenetic significance is still not completely understood $[9,11]$. In addition to their presence in patients with RA, RFs have been 
detected in the gingiva, subgingival plaque, saliva, and serum of patients with PD [26, 27], and are thought, through complement activation, to help modulate the immune response in periodontal lesions [28].

The antibody system that may directly link the shared pathogenesis of RA and PD is the ACPA. ACPAs are immunoglobulins that are highly specific for the diagnosis of RA [8, 29]. Although the direct role of ACPA in RA is not entirely understood, it has become clear that post-translational changes to proteins occur in sites of tissue injury or inflammation [30, 31]. These post-translational modifications, which include citrullination, alter the biochemical and antigenic nature of the peptide structure, exposing neo-epitopes, and result in the generation of autoantibodies to these altered peptides [32]. There are at least five isotypes of the mammalian enzyme (peptidylarginine deiminase [PAD]) capable of inducing citrullination of mammalian proteins (PAD-1, 2, 3, 4, and 6) [33]. In humans, PAD-2 and PAD-4 are associated with the production of citrullinated proteins in RA [34]. In genetically predisposed individuals - possibly due to binding of citrullinated peptides to the shared epitope - generation of ACPAs is directed toward particular citrullinated proteins (e.g., $\alpha$-enolase, vimentin, fibrinogen, and type II collagen). Studies have identified ACPA levels as specific serological markers for RA that correlate with disease severity as well as the development of erosive and extra-articular disease [35-37]. In some RA patients, ACPA can be detected in the circulation many years prior to the development of clinically manifest disease (i.e., preclinical RA) [38, 39]. During this phase, the synovial architecture shows little or no indication of inflammation or activation of immune cells [40-42].

In 2004, after the clinical utility of ACPA in the diagnosis and prognosis of RA and the elucidation of the enzymatic apparatus of $P$. gingivalis had been established [43], we proposed that it was actually the humoral immune response to $P$. gingivalis that provided a stimulus for the development of RA [44]. We posited that periodontitis, and exposure to $P$. gingivalis and its own PAD (PPAD), could break immune tolerance and trigger a latent antibody response against citrullinated proteins prior to the onset of RA [44]. PPAD is unique to $P$. gingivalis and shares sequence homology with other bacterial arginine deiminases, and is not evolutionarily related to the mammalian family of PAD enzymes [43].

P. gingivalis has been identified in subgingival biofilms of patients with RA. With the use of high-throughput bacterial DNA sequencing, Scher et al. showed that about $55 \%$ of newonset untreated RA patients carried $P$. gingivalis, twice as many as seen among healthy controls [24••]. Other groups have also reported a trend toward increased incidence of $P$. gingivalis in patients with RA [45••], particularly early in the disease course $[46 \bullet \bullet, 47 \bullet \cdot]$.

In addition to PPAD, recent studies have confirmed the presence of PAD-2 and PAD-4 in inflamed periodontal tissues
[48, 49]. Wegner et al. demonstrated that through PPAD, $P$. gingivalis could induce citrullination in both bacterial and host peptides, such as fibrinogen and $\alpha$-enolase. The ability to generate citrullinated peptides by both host and bacterial PAD in periodontal tissues provides strong evidence of a role for periodontal citrullination in the pathogenesis of RA [50] $P$. gingivalis has also been shown to have an enolase, which when auto-citrullinated results in antibodies that are able to cross-react with antibodies to $\alpha$-enolase found in RA patients [51]. Antibodies to $P$. gingivalis have been shown to correlate with the presence of ACPAs in patients with RA and their family members [52]. Even in the absence of RA, ACPAs have been reported in the serum of individuals suffering from $\operatorname{PD}[35,53]$. Thus, there is considerable potential for significant citrullination to occur within inflamed periodontal tissues. The generation of ACPA directed against periodontal antigens may thus prime susceptible individuals to a heightened ACPA reaction, often directed toward additional targets, as a consequence of epitope spreading prior to RA disease onset $[37,54,55,56 \bullet \bullet$.

The ACPA link between PD and RA appears to be a twoway street, in that the predilection for ACPA formation in patients with RA seems to be linked to the degree of alveolar bone loss. The University of Nebraska group recently published studies assessing the incidence of PD among patients with RA and correlation with RA disease activity and serologies. The degree of alveolar bone loss was associated with ACPA levels, clinical and radiographic measures of RA disease activity, and level of disability. Alveolar bone loss was associated with the presence of ACPAs targeting citrullinated vimentin and histone. The levels of specific ACPAs were associated with the presence of subgingival $P$. gingivalis and with higher levels of anti-P. gingivalis antibodies $[25 \bullet \bullet, 46 \bullet \cdot$.

The centrality of citrullination in both PD and RA has been demonstrated by recent animal studies. Preexistent periodontitis was shown to exacerbate experimental arthritis in a murine model [57••]. Infection with viable $P$. gingivalis exacerbated collagen-induced arthritis, and was linked with the presence of PPAD [58・•]. In another murine model of both PD and RA, PPAD-deficient strains of $P$. gingivalis were associated with significantly reduced periodontal inflammation and lowered ACPA levels, in addition to a reduction in joint swelling and radiographic damage [59••].

\section{Effects of Periodontitis Treatment on Rheumatoid Arthritis Outcomes}

Periodontal care involving scaling and root planing to eliminate dental plaque and calculus formation has been shown not only to improve local gingival and periodontal inflammation, but to reduce systemic mediators of inflammation that might underlie the association of PD with atherosclerosis and other 
systemic conditions [60]. Furthermore, if PD is a contributor to the underlying systemic inflammatory process in RA, the expectation would be that periodontal care should help ameliorate RA disease activity.

Several studies have now demonstrated that nonsurgical periodontal treatment is able to reduce serum TNF- $\alpha$, IL-6, and C-reactive protein levels, and to moderate RA disease activity, in patients with moderate to severe PD [60-62]. Ortiz et al. evaluated disease outcomes in 40 RA patients, half of whom were treated with conventional disease-modifying antirheumatic drugs (DMARDs), and half who received DMARDs and anti-TNF treatment. Patients in each group were randomized to either scaling and root planing or no PD treatment. Those who received PD treatment showed a significant decrease in clinical measures of RA disease activity and laboratory abnormalities compared with those without PD therapy. Interestingly, those who received anti-TNF therapy showed improvement in clinical PD activity [61]. Similar findings indicating improved RA outcomes in patients receiving nonsurgical PD therapy have been demonstrated in studies from other geographic regions [62-64, 65••, 66, 67]. Another study, in RA patients who were about to commence biologic treatment, found that good RA outcomes were only achieved in patients without established PD, suggesting that the presence of PD could interfere with the success of anti-TNFtherapy $[65 \cdot \bullet]$.

Bartold's group performed a meta-analysis of five studies [6, $61,62,64,67]$ and similarly concluded that nonsurgical periodontal treatment could lead to improvement in markers of disease activity in RA, noting that the studies were of short duration ( $<6$ months), included few subjects, and did not sufficiently assess potentially confounding comorbidities [68••].

\section{Effects of Rheumatoid Arthritis Treatment on Periodontitis Outcomes}

Pharmacological treatment of RA involves the use of DMARDs. Methotrexate is the drug most often utilized, and is often characterized as the foundation upon which other therapeutic decisions are made. The history of DMARD treatment of RA, however, has witnessed an evolution, from the empirical use of small molecules, often thought to treat possible infectious agents (gold salts, antimalarials [hydroxychloroquine], and sulfasalazine), to broad-spectrum immunomodulatory medications (methotrexate, cyclosporine, and leflunomide), to biologic therapies (monoclonal antibodies, soluble receptors, fusion proteins) that target specific proinflammatory cytokines (TNF- $\alpha$, IL-1, IL-6) or cell surface molecules, which either define cell populations that can be depleted (i.e., CD20 on B lymphocytes) or are required for $\mathrm{T}$ cell co-stimulation and activation. The use of several available biologic agents, either alone or in conjunction with methotrexate, has dramatically reduced the rate of joint destruction that is linked with disability as well as mortality in RA. Since RA and PD share several common pathogenic mechanisms, and since treatment of PD may exert a beneficial effect upon RA (see above), one might expect that treatments that are effective in RA would also improve PD.

There is substantial evidence for the utility of the prostaglandin inhibitors, non-steroidal anti-inflammatory drugs (NSAIDs) in the treatment of both conditions. However, NSAIDs have not been determined to have diseasemodifying effects in the treatment of RA, and will not be further reviewed here [69].

Of medications that do have clinical evidence for disease modification in RA, the semi-synthetic tetracyclines (minocycline and doxycycline) presumably work through both anti-inflammatory pathways and inhibition of collagenase and other matrix metalloproteinases, as has been demonstrated for subantimicrobial concentrations of tetracyclines in treatment of PD [70]. Despite substantial laboratory evidence of their effectiveness as inhibitors and successful, albeit small, clinical trials [71], these medications have not been perceived to have a major clinical benefit and are not commonly used in the treatment of RA [72].

With the exception of rare case reports, information on the effects of other small-molecule DMARDs on PD is limited to a few animal studies evaluating the effects of gold and methotrexate. In a ligature-induced experimental model of PD in squirrel monkeys, maintaining therapeutic levels of gold salts (gold sodium thiomalate, $5 \mathrm{mg} / \mathrm{kg}$ every 4 days for 12 days) resulted in smaller areas of infiltrated supracrestal connective tissue, less loss of connective tissue attachment, and less coronal alveolar bone loss compared with placebo [73]. This disease-modifying effect appeared to be related to a selective decrease in infiltrating polymorphonuclear (PMN) leukocytes, presumably due to gold's inhibitory effect on PMN chemotaxis [74]. In a similar model of periodontitis in Wistar rats, intraperitoneal administration of methotrexate at doses of $0.1 \mathrm{mg} / \mathrm{kg}, 0.5 \mathrm{mg} / \mathrm{kg}$ (doses in a range approximating those used to treat RA), and $1 \mathrm{mg} / \mathrm{kg}$ (a dose sufficient to cause neutropenia) for 28 days was no more effective than placebo in preventing alveolar bone loss [75].

The TNF- $\alpha$ inhibitors were the first biologics introduced for the treatment of RA, and remain the first-line and most commonly prescribed biologics for this disorder. There have been no placebo-controlled trials of TNF inhibitors for PD, and disappointingly, the few clinical trials of this class of biologics reported to date have yielded conflicting and - at best - only suggestive evidence of a possible beneficial effect on PD. In an observational study of RA patients treated with infliximab (a chimeric anti-TNF monoclonal antibody), antiTNF- $\alpha$-naïve RA patients, and healthy controls (10 in each group), infliximab-treated patients had significantly less attachment loss $(p=0.027)$ than TNF- $\alpha$-naïve and healthy 
controls and, as might have been predicted, lower levels of TNF- $\alpha$ in gingival crevicular fluid. [76]. In a cross-sectional study in which 20 RA patients who had received a mean 40 months of therapy with infliximab were compared with 20 infliximab-naïve subjects, treatment with infliximab was associated with a significant increase in gingival inflammation as assessed by modified gingival score and papillary bleeding index, but had no effect on the severity of PD as judged by attachment loss and probing depth. From the group of 20 infliximab-naïve patients, nine patients with PD were then treated with infliximab for nine months and reevaluated. While an increase in gingival inflammation was seen once again, confirming observations from the cross-sectional part of the study, the clinical attachment loss was significantly $(p<0.05)$ reduced after treatment with infliximab, while probing depth remained constant. [77]. Quite opposite effects were recently reported for adalimumab (a fully humanized antiTNF monoclonal antibody). Among 20 Japanese RA patients treated for three months, a significant improvement in measures of gingivitis (gingival index, bleeding on probing) was seen. While there was a significant reduction in probing depth, however, no effect upon clinical attachment level was observed [78].

An impressive effect of IL-6 inhibition on PD was evaluated in a unique eight-week clinical trial in which $28 \mathrm{RA}$ patients who had completed 20 months of therapy with tocilizumab, and 27 RA biologic DMARD-naïve "control" patients, were evaluated at baseline for clinical (gingival index, bleeding on probing, probing depth, clinical attachment level) and biomarker PD parameters (serum IL-6, MMP-3 levels). RA disease activity was also evaluated by a composite clinical and laboratory assessment. These clinical and biomarker studies were repeated eight weeks later while patients continued their treatment regimens. Thus this study, unlike the anti-TNF trials, approximated a placebo-controlled trial. Patients treated with tocilizumab showed a significantly greater decrease in gingival index $(p<0.01)$, bleeding on probing $(p<0.003)$, probing depth $(p<0.0001)$, and clinical attachment level $(p<0.005)$ compared to the control group. This robust effect on all aspects of PD clinical activity occurred while only a trend toward improvement in RA disease activity $(p<0.06)$ was observed [79••].

Modulation of $\mathrm{T}$ cell activation through inhibition of the B7-CD28 costimulatory pathway has provided another therapeutic target in RA with the use of abatacept, a CTLA4-IgG Fc fragment fusion protein that inhibits interaction between $\mathrm{B} 7$ (CD80/86) expressed on antigen-presenting cells with CD28 expressed on CD4 helper T cells. A requirement for B7 costimulation was demonstrated in a cell transfer model of antigen and LPS-induced PD in rodents. The inhibition of alveolar bone loss in this model with either local or systemic administration of CTLA4-Ig suggested that abatacept treatment of RA could also ameliorate PD [80]. To date, no human clinical trials have been conducted. The effect of B cell depletion with rituximab has not yet been studied in PD.

In conclusion, there are no data in humans to assess the effects of non-biologic DMARDs on PD. Although there is more information from a limited number of studies of biologic DMARDS, the number of patients studied has been small, and there have been no randomized double-blind placebo-controlled trials. The use of anti-TNF antibodies has not consistently prevented alveolar bone loss, and has either aggravated or improved gingival inflammation, depending upon which drug was used. Whether these divergent results reflect differences in structure of the anti-TNFs studied (infliximab is chimeric and adalimumab is fully humanized) is not clear. To date, the most impressive beneficial effect was seen with IL-6 inhibition reported with tocilizumab, an IL-6 receptor antibody. Further studies with tocilizumab, as well as observations with the use of anti-IL- 6 antibodies, may further elucidate the importance of this particular cytokine in the pathogenesis of PD.

\section{Periodontal Disease is not Sine qua non for Development of Rheumatoid Arthritis}

One can make a compelling argument for PD as a proximate contributing factor in the breakdown of tolerance to citrullinated proteins and the ultimate development of RA. But PD is neither necessary nor sufficient for the development of RA. We have noted that the preponderance of data connecting PD and RA is reserved for those patients that are seropositive (ACPA-positive) and likely possess the shared epitope, the major genetic predisposition for the development of RA. These connections may not apply to patients who are seronegative. Furthermore, many of the studies that have supported this clinical association are fraught with potential inaccuracies - small sample size, lack of uniformity in the definitions of PD and RA (patients asked to self-identify their underlying condition, or no measurement of the associated serologic abnormalities [RF or ACPA] to substantiate the diagnosis), and clinical settings that likely represent a disparate population (e.g., Veterans Administration Medical Centers likely to have an abundance of male patients) [81].

Perhaps other oral organisms serve as antigenic triggers and contribute to the development of RA, either independently or in conjunction with $P$. gingivalis. Scher et al. identified additional oral pathogens that correlate with either the development of RA-associated autoantibodies (Anaeroglobus geminatus) or early RA (i.e., Prevotella, Leptotrichia, and Tannerella species) [24••]. Using a murine model of PD and RA, de Aquino et al. were able to generate subgingival and synovial inflammation, requiring the presence of both P. gingivalis and Prevotella nigrescens [82••]. 
Other mucosal sites exposed to high loads of bacterial antigens, such as lung and gut, may represent alternative sites of generation of immune stimulation and autoimmune reactants $[83 \cdot 0]$. The lung is particularly suspect, as recent epidemiological data, particularly in the context of genetic predisposition (shared epitope) and ACPA seropositivity, support a connection with tobacco smoking [84]. It is well known that smoking is a risk factor for periodontal inflammation and destruction [85], but smoking also turns out to be the bestestablished environmental risk factor for development of RA. Smoking raises the risk of seropositivity not only in RA patients, but also among smokers with aggressive PD without clinical evidence of RA [86, 87••]. Population-based casecontrol studies [88] have shown that smokers have twice the risk of developing seropositive RA compared with neversmokers, and the risk is dose-dependent on lifetime exposure to smoking $[89,90]$. Bronchiectasis has also been identified as a risk factor for RA, with a tenfold higher prevalence compared to osteoarthritic patients [91] and an association with elevated levels of ACPA [92••]. In studies utilizing highresolution computed tomography of the lungs, ACPA positivity in the absence of clinical arthritis has been associated with greater airway abnormalities than seen with seronegative individuals [93]. In a manner analogous to Weissmann's hypothesis regarding the role of sugar and the risk of RA [14], Aceves-Avila suggested that the availability of tobacco may have altered the predisposition to RA among European populations [94].

Alterations in intestinal microbiome homeostasis have also been linked with the development of RA [95]. Some studies have demonstrated an association with a reduction in fecal bacterial counts or a greater diversity of Lactobacillus varieties in patients with early RA [96]. Scher's group documented an abundance of Prevotella copri among RA patients, identifying the organism in $75 \%$ of patients with new-onset RA, compared to $13 \%$ of the non-affected population [24••].

\section{Rheumatoid Arthritis: The Elusive Second Hit}

The relationship between PD and RA has been hypothesized to represent a "two-hit" model [19, 97, 98]. Whether one accepts the breakdown of tolerance due to citrullination in the periodontium [44], or identifies the lungs as the source of ACPA or the gut as a site of immune dysregulation representing the "first hit," there remains tremendous uncertainty as to how disease manifestations materialize in the joints. The second joint "insult," whether infectious or biomechanical or microvascular, has yet to be identified. It has been proposed that oral pathogens can directly inoculate the joints, with reports of detection of DNA from $P$. gingivalis isolated from rheumatoid synovium [99]. The relevance of this remains unclear, without identifying histological or microbiological evidence of an active anaerobic septic arthritis. Local production of ACPA directed against type II collagen, fibrinogen, $\alpha$-enolase, or vimentin may occur as citrullinated neo-epitopes of these proteins have been detected in the joints of animal models of RA and in RA patients [100, $101 \bullet \cdot, 102]$. ACPAs may also be first generated or propagated by neutrophil cell death or NETosis, which results in posttranslational citrullination of histones and the extracellular release of chromatin, and occurs at the site of tissue injury and inflammation [103••, 104]. Yet the presence of ACPA cannot simply be a nonspecific result of synovial inflammation, as citrullinated peptides and ACPAs seem to be absent from synovial tissue in inflammatory and non-inflammatory joint diseases other than RA [32].

Similarly, other autoantibody systems have been implicated in the development of RA. Antibodies that recognize carbamylated proteins (anti-CarPA) that are generated against peptides that have been homocitrullinated (post-translational modification of lysine residues) have been identified in RA patients $[105,106]$. In an animal model, the presence of antiCarPA increased susceptibility to synovitis in the presence of citrullinated peptides [107]. This mechanism is particularly attractive in that carbamylated proteins have been identified in inflamed gingival tissue, and may further link the presence of PD with the development of RA [108].

Other infectious agents and their products (heat shock proteins) have been found to be associated with the development of RA, with molecular mimicry often the postulated connection [2, 9]. In particular, infection with an arthritogenic strain of virus (e.g., parvovirus B19) [109] or accumulation of Epstein-Barr virus-activated immune cells in synovium may serve as the stimulus for synovial inflammation [110].

\section{Rheumatoid Arthritis and Periodontal Disease: Practical Recommendations}

With the availability of biologic DMARDs and the potential to achieve more profound disease control, a more aggressive approach to managing RA has been adopted (i.e., "treat to target") [111]. If we are to accomplish that goal, we cannot lose sight of the non-pharmacologic measures that might favorably impact disease control [112].

- Fatty acid supplementation: The anti-inflammatory potential of diets rich in select n-3 and n-6 polyunsaturated fatty acids, which can alter eicosanoid production, has been demonstrated in vitro and in many disease states. Supplementation with borage seed oil as a source of gamma-linolenic acid, and fish oil for eicosapentaenoic acid and docosahexaenoic acid, has been shown to improve outcomes in RA patients by decreasing the need for TNF antagonist use, improving the response to 
combination DMARD therapy, and achieving a higher rate of clinical remission [113, 114]. Benefits have also been shown in the treatment of PD $[115,116]$.

- Smoking cessation: Although the connection between smoking and RA is well-substantiated [117], the beneficial effects of smoking cessation are less clear [118]. However, a recent study in women demonstrated that the risk of RA decreases over time after smoking cessation [119], and smoking cessation seems to improve outcomes in PD as well [120].

- Weight loss: Likewise, studies have supported a connection between overweight/obesity status and RA disease activity, disability, and the likelihood of achieving good disease control [121, 122]. Although weight loss has yet to be shown to improve RA disease activity, in light of the excess cardiovascular morbidity seen in RA patients, weight loss regimens should be instituted in order to reduce modifiable risk factors. Similarly, PD has been associated with cardiovascular morbidities, and obesity has also been linked with development of PD [123].

- Evaluation and treatment of periodontal disease: As summarized above, Bartold's group concluded that nonsurgical periodontal treatment can improve RA disease activity. Furthermore, the response of RA to anti-TNF therapy can be abrogated by the presence of PD [65••, 68••]. Early referral for dental evaluation and treatment may improve the course of RA [47••].

\section{Conclusions}

Although there is compelling data supporting a link between the development of PD and RA, cementing the association will require further extensive investigative work. In particular, this will include longitudinal observational studies and microbiome analysis to elucidate the temporal relationship between PD and RA; manipulations of the activity of PPAD in P. gingivalis and the development of ACPA; interventional (pharmacologic or immunization) trials in PD-RA experimental animal models; and ultimately, the treatment of subclinical PD in individuals at highest risk for development of RA (e.g., monozygotic twins, ACPA-seropositive first-degree family members).

As rheumatologists, we now discuss the possibility of remission with RA patients. A successful understanding of the link between PD and RA offers the prospect of soon discussing the prevention of RA.

\section{Compliance with Ethics Guidelines}

Conflict of Interest Elliot D. Rosenstein, Laura J. Kushner, and Neil Kramer each declare that they have no conflict of interest.
Human and Animal Rights and Informed Consent This article does not contain any studies with animal subjects performed by any of the authors. With regard to the authors' research cited in this paper, all procedures were followed in accordance with the ethical standards of the responsible committee on human experimentation and with the 1975 Declaration of Helsinki, as revised in 2000 and 2008.

\section{References}

Papers of particular interest, published recently, have been highlighted as:

•• Of major importance

1. Snyderman R, McCarty GA. Analogous mechanisms of tissue destruction in rheumatoid arthritis and periodontal disease. In: Genco RJ, Mergenhagen SE, editors. Host-parasite interaction in periodontal diseases. Washington: American Society of Microbiology; 1982. p. 354-62.

2. Firestein GS. Evolving concepts of rheumatoid arthritis. Nature. 2003;423:356-61.

3. Looper KJ, Mustafa SS, Zelkowitz P, Purden M, Baron M. Work instability and financial loss in early inflammatory arthritis. Int J Rheum Dis. 2012;15:546-53.

4. de Croon EM, Sluiter JK, Nijssen TF, Dijkmans BA, Lankhorst GJ, Frings-Dresen MH. Predictive factors of work disability in rheumatoid arthritis: a systematic literature review. Ann Rheum Dis. 2004;63:1362-7.

5. Guedes C, Dumont-Fischer D, Leichter-Nakache S, Boissier MC. Mortality in rheumatoid arthritis. Rev Rhum Engl Ed. 1999;66: 492-8.

6. Okada Y, Wu D, Trynka G, Raj T, Terao C, Ikari K, et al. Genetics of rheumatoid arthritis contributes to biology and drug discovery. Nature. 2014;506:376-81.

7. Gregersen PK, Silver J, Winchester RJ. The shared epitope hypothesis. An approach to understanding the molecular genetics of susceptibility to rheumatoid arthritis. Arthritis Rheum. 1987;30: 1205-13.

8. Pratesi F, Petit Teixeira E, Sidney J, Michou L, Puxeddu I, Sette A, et al. HLA shared epitope and ACPA: just a marker or an active player? Autoimmun Rev. 2013;12:1182-7.

9. McInnes IB, Schett G. The pathogenesis of rheumatoid arthritis. N Engl J Med. 2011;365:2205-19.

10. Peschken CA, Hitchon CA, Robinson DB, Smolik I, Barnabe CR, Prematilake S, et al. Rheumatoid arthritis in a North American native population: longitudinal follow-up and comparison with a white population. J Rheumatol. 2010;37:1589-95.

11. del Puente A, Knowler WC, Pettitt DJ, Bennett PH. The incidence of rheumatoid arthritis is predicted by rheumatoid factor titer in a longitudinal population study. Arthritis Rheum. 1988;31:1239 44.

12. Davidson A, Keiser HD, del Puente A, Bennett PH, Schrohenloher R, Koopman WJ. Expression of rheumatoid factor idiotypes $17.109,6 \mathrm{~B} 6.6$ and 4C9 in the sera of Pima Indians. Autoimmunity. 1994;18:251-8.

13. Rothschild BM, Woods RJ, Rothschild C, Sebes JI. Geographic distribution of rheumatoid arthritis in ancient North America: implications for pathogenesis. Semin Arthritis Rheum. 1992;22: $181-7$.

14. Weissmann G. The pathogenesis of rheumatoid arthritis. Bull NYU Hosp Jt Dis. 2006;64:12-5.

15. Bonfil JJ, Dillier FL, Mercier P, Reviron D, Foti B, Sambuc R, et al. A "case control" study on the role of HLA DR4 in severe 
periodontitis and rapidly progressive periodontitis. Identification of types and subtypes using molecular biology. J Clin Periodontol. 1999;26:77-84.

16. Skrepcinski FB, Niendorff WJ. Periodontal disease in American Indians and Alaska Natives. J Public Health Dent. 2000;60 Suppl 1:261-6.

17. Emrich LJ, Schlossman M, Genco RJ. Periodontal disease in noninsulin-dependent diabetes mellitus. J Periodontol. 1991;62:12331.

18. Hunter W. Oral sepsis as a cause of disease. Br Med J. 1900;2: 215-6.

19. Bartold PM, Marshall RI, Haynes DR. Periodontitis and rheumatoid arthritis: a review. J Periodontol. 2005;76:2066-74.

20. Greenwald RA, Kirkwood K. Adult periodontitis as a model for rheumatoid arthritis (with emphasis on treatment strategies). J Rheumatol. 1999;26:1650-3.

21. Mercado FB, Marshall RI, Klestov AC, Bartold PM. Relationship between rheumatoid arthritis and periodontitis. J Periodontol. 2001;72:779-87.

22. Dissick A, Redman RS, Jones M, Rangan BV, Reimold A, Griffiths GR, et al. Association of periodontitis with rheumatoid arthritis: a pilot study. J Periodontol. 2010;81:223-30.

23. de Pablo P, Dietrich T, McAlindon TE. Association of periodontal disease and tooth loss with rheumatoid arthritis in the US population. J Rheumatol. 2008;35:70-6.

24.• Scher JU, Ubeda C, Equinda M, Khanin R, Buischi Y, Viale A, et al. Periodontal disease and the oral microbiota in new-onset rheumatoid arthritis. Arthritis Rheum. 2012;64:3083-94. Patients with $R A$ exhibited a high prevalence of PD early in the disease and despite the paucity of smoking history. Although colonization with $P$ gingivalis correlated with the severity of $P D$, other oral pathogens might have a contributory role.

25.• Gonzalez SM, Payne JB, Yu F, Thiele GM, Erickson AR, Johnson $\mathrm{PG}$, et al. Alveolar bone loss is associated with circulating anticitrullinated protein antibody (ACPA) in rheumatoid arthritis patients. J Periodontol. 2014;9:1-16. The degree of alveolar bone loss was associated with higher ACPA levels, analogous to what is found at articular sites.

26. Hirsch HZ, Tarkowski A, Koopman WJ, Mestecky J. Local production of IgA- and IgM-rheumatoid factors in adult periodontal disease. J Clin Immunol. 1989;9:273-8.

27. Thé J, Ebersole JL. Rheumatoid factor (RF) distribution in periodontal disease. J Clin Immunol. 1991;11:132-42.

28. Hara Y, Kaneko T, Yoshimura A, Kato I. Serum rheumatoid factor induced by intraperitoneal administration of periodontopathic bacterial lipopolysaccharide in mice. J Periodontal Res. 1996;31:502-7.

29. Schellekens GA, Visser H, de Jong BA, van den Hoogen FH, Hazes JM, Breedveld FC, et al. The diagnostic properties of rheumatoid arthritis antibodies recognizing a cyclic citrullinated peptide. Arthritis Rheum. 2000;43:155-63.

30. Gyorgy B, Toth E, Tarcsa E, Falus A, Buzas EI. Citrullination: a posttranslational modification in health and disease. Int J Biochem Cell Biol. 2006;38:1662-77.

31. Wang Y, Li M, Stadler S, Correll S, Li P, Wang D, et al. Histone hypercitrullination mediates chromatin decondensation and neutrophil extracellular trap formation. J Cell Biol. 2009;184:205-13.

32. Masson-Bessière C, Sebbag M, Girbal-Neuhauser E, Nogueira L, Vincent C, Senshu T, et al. The major synovial targets of the rheumatoid arthritis-specific antifilaggrin autoantibodies are deiminated forms of the alpha- and beta-chains of fibrin. $\mathrm{J}$ Immunol. 2001;166:4177-84.

33. Bicker KL, Thompson PR. The protein arginine deiminases: structure, function, inhibition, and disease. Biopolymers. 2013;99:155-63.

34. Foulquier C, Sebbag M, Clavel C, Chapuy-Regaud S, Al Badine $\mathrm{R}$, Méchin MC, et al. Peptidyl arginine deiminase type 2 (PAD-2) and PAD-4 but not PAD-1, PAD-3, and PAD-6 are expressed in rheumatoid arthritis synovium in close association with tissue inflammation. Arthritis Rheum. 2007;56:3541-53.

35. El-Gabalawy HS, Robinson DB, Hart D, Elias B, Markland J, Peschken CA, et al. Immunogenetic risks of anti-cyclical citrullinated peptide antibodies in a North American Native population with rheumatoid arthritis and their first-degree relatives. J Rheumatol. 2009;36:1130-5.

36. Kroot EJ, de Jong BA, van Leeuwen MA, Swinkels H, van den Hoogen FH, van't Hof M, et al. The prognostic value of anti-cyclic citrullinated peptide antibody in recent-onset rheumatoid arthritis. Arthritis Rheum. 2000;43:1831-5.

37. Rantapää-Dahlqvist S, de Jong BA, Berglin E, Hallmans G, Wadell G, Stenlund H, et al. Antibodies against cyclic citrullinated peptide and IgA rheumatoid factor predict the development of rheumatoid arthritis. Arthritis Rheum. 2003;48:2741-9.

38. Nielen MM, van Schaardenburg D, Reesink HW, van de Stadt RJ, van der Horst-Bruinsma IE, de Koning MH, et al. Specific autoantibodies precede the symptoms of rheumatoid arthritis: a study of serial measurements in blood donors. Arthritis Rheum. 2004;50:380-6.

39. Arkema EV, Goldstein BL, Robinson W, Sokolove J, Wagner CA, Malspeis S, et al. Anti-citrullinated peptide autoantibodies, human leukocyte antigen shared epitope and risk of future rheumatoid arthritis: a nested case-control study. Arthritis Res Ther. 2013;15: R159.

40. van de Sande MG, de Hair MJ, Schuller Y, van de Sande GP, Wijbrandts CA, Dinant HJ, et al. The features of the synovium in early rheumatoid arthritis according to the 2010 ACR/EULAR classification criteria. PLoS One. 2012;7:e36668.

41. de Hair MJ, van de Sande MG, Ramwadhdoebe TH, Hansson M, Landewé R, van der Leij C, et al. Features of the synovium of individuals at risk of developing rheumatoid arthritis: implications for understanding preclinical rheumatoid arthritis. Arthritis Rheum. 2014;66:513-22.

42. Wegner N, Lundberg K, Kinloch A, Fisher B, Malmstrom V, Feldmann M, et al. Autoimmunity to specific citrullinated proteins gives the first clues to the etiology of rheumatoid arthritis. Immunol Rev. 2010;233:34-54.

43. McGraw WT, Potempa J, Farley D, Travis J. Purification, characterization, and sequence analysis of a potential virulence factor from Porphyromonas gingivalis, peptidylarginine deiminase. Infect Immun. 1999;67:3248-56.

44. Rosenstein ED, Greenwald, Kushner LJ, Weissmann G. Hypothesis: the humoral immune response to oral bacteria provides a stimulus for the development of rheumatoid arthritis. Inflammation. 2004;28:311-8.

45.• Mikuls TR, Thiele GM, Deane KD, Payne JB, O'Dell JR, Yu F, et al. Porphyromonas gingivalis and disease-related autoantibodies in individuals at increased risk of rheumatoid arthritis. Arthritis Rheum. 2012;64:3522-30. Immunity to P. gingivalis is significantly associated with $R A$ autoantibodies in those at risk of $R A$, supporting its role in the loss of tolerance.

46.• Mikuls TR, Payne JB, Yu F, Thiele GM, Reynolds RJ, Cannon GW, et al. Periodontitis and Porphyromonas gingivalis in patients with rheumatoid arthritis. Arthritis Rheum. 2014;66:1090-100. Periodontal disease and P. gingivalis appear to have independent and additive effects on the development of $R A$.

47.• Wolff B, Berger T, Frese C, Max R, Blank N, Lorenz HM, et al. Oral status in patients with early rheumatoid arthritis: a prospective, case-control study. Rheumatology (Oxford). 2014;53:52631. Loss of periodontal attachment and alveolar bone loss can be identified in patients with early $R A$.

48. Harvey GP, Fitzsimmons TR, Dhamarpatni AA, Marchant C, Haynes DR, Bartold PM. Expression of peptidylarginine deiminase- 2 and -4 , citrullinated proteins and anti-citrullinated 
protein antibodies in human gingiva. J Periodontal Res. 2013;48: $252-61$.

49. Nesse W, Westra J, van der Wal JE, Abbas F, Nicholas AP, Vissink A, et al. The periodontium of periodontitis patients contains citrullinated proteins which may play a role in ACPA (anticitrullinated protein antibody) formation. J Clin Periodontol. 2012;39:599-607.

50. Wegner N, Wait R, Sroka A, Eick S, Nguyen KA, Lundberg K, et al. Peptidylarginine deiminase from Porphyromonas gingivalis citrullinates human fibrinogen and $\alpha$-enolase: implications for autoimmunity in rheumatoid arthritis. Arthritis Rheum. 2010;62: 2662-72.

51. Lundberg K, Kinloch A, Fisher BA, Wegner N, Wait R, Charles P, et al. Antibodies to citrullinated alpha-enolase peptide 1 are specific for rheumatoid arthritis and cross-react with bacterial enolase. Arthritis Rheum. 2008;58:3009-19.

52. Hitchon CA, Chandad F, Ferucci ED. Antibodies to Porphyromonas gingivalis are associated with anticitrullinated protein antibodies in patients with rheumatoid arthritis and their relatives. J Rheumatol. 2010;37:1105-13.

53. Smit MD, Westra J, Vissink A, Doornbos-van der Meer B, Brouwer E, van Winkelhoff AJ. Periodontitis in established rheumatoid arthritis patients: a cross-sectional clinical, microbiological and serological study. Arthritis Res Ther. 2012; 14:R222.

54. Brink M, Hansson M, Mathsson L, Jakobsson PJ, Holmdahl R, Hallmans G, et al. Multiplex analyses of antibodies against citrullinated peptides in individuals prior to development of rheumatoid arthritis. Arthritis Rheum. 2013;65:899-910.

55. van der Woude D, Rantapää-Dahlqvist S, Ioan-Facsinay A, Onnekink C, Schwarte CM, Verpoort KN, et al. Epitope spreading of the anti-citrullinated protein antibody response occurs before disease onset and is associated with the disease course of early arthritis. Ann Rheum Dis. 2010;69:1554-61

$56 . •$ de Pablo P, Dietrich T, Chapple IL, Milward M, Chowdhury M, Charles PJ, et al. The autoantibody repertoire in periodontitis: a role in the induction of autoimmunity to citrullinated proteins in rheumatoid arthritis? Ann Rheum Dis. 2014;73:580-6. The initial antibody response in periodontitis may be directed against uncitrullinated peptides of the $R A$ autoantigens. Through epitope spreading to citrullinated epitopes, loss of tolerance leading to presymptomatic $R A$ could be established.

57.• Cantley MD, Haynes DR, Marino V, Bartold PM. Pre-existing periodontitis exacerbates experimental arthritis in a mouse model. J Clin Periodontol. 2011;38:532-41. P. gingivalis induced PD exacerbated arthritis in a mouse model of $R A$.

58.• Maresz KJ, Hellvard A, Sroka A, Adamowicz K, Bielecka E, Koziel J, et al. Porphyromonas gingivalis facilitates the development and progression of destructive arthritis through its unique bacterial peptidylarginine deiminase (PAD). PLoS Pathog. 2013;9:e1003627. P. gingivalis PPAD has a direct role in the development and progression of $R A$.

59.• Gully N, Bright R, Marino V, Marchant C, Cantley M, Haynes D, et al. Porphyromonas gingivalis peptidylarginine deiminase, a key contributor in the pathogenesis of experimental periodontal disease and experimental arthritis. PLoS One. 2014;9:e100838. The use of a PPAD deficient strain of P. gingivalis PPAD resulted in reduced periodontal inflammation and lessened arthritis as compared to the wild-type in an experimental model of $R A$.

60. D'Aiuto F, Nibali L, Parkar M, Suvan J, Tonetti MS. Short term effects of intensive periodontal therapy on serum inflammatory markers and cholesterol. J Dent Res. 2005;84:269-73.

61. Ortiz P, Bissada NF, Palomo L, Han YW, Al-Zahrani MS, Panneerselvam A, et al. Periodontal therapy reduces the severity of active rheumatoid arthritis in patients treated with or without tumor necrosis factor inhibitors. J Periodontol. 2009;80:535-40.
62. Ribeiro J, Leão A, Novaes AB. Periodontal infection as a possible severity factor for rheumatoid arthritis. J Clin Periodontol. 2005;32:412-6.

63. Erciyas K, Sezer U, Ustün K, Pehlivan Y, Kisacik B, Senyurt SZ, et al. Effects of periodontal therapy on disease activity and systemic inflammation in rheumatoid arthritis patients. Oral Dis. 2013;19:394-400.

64. Al-Katma MK, Bissada NF, Bordeaux JM, Sue J, Askari AD. Control of periodontal infection reduces the severity of active rheumatoid arthritis. J Clin Rheumatol. 2007;13:134-7.

65.• Savioli C, Ribeiro AC, Fabri GM, Calich AL, Carvalho J, Silva $\mathrm{CA}$, et al. Persistent periodontal disease hampers anti-tumor necrosis factor treatment response in rheumatoid arthritis. J Clin Rheumatol. 2012;18:180-4. The persistence of periodontal inflammation may interfere with the effectiveness of biologic $D M A R D$ therapy in patients with $R A$, preventing effective disease control.

66. Okada M, Kobayashi T, Ito S, Yokoyama T, Abe A, Murasawa A, et al. Periodontal treatment decreases levels of antibodies to Porphyromonas gingivalis and citrulline in patients with rheumatoid arthritis and periodontitis. J Periodontol. 2013;84:e74-84.

67. Pinho MN, Oliveira RD, Novaes Jr AB, Voltarelli JC. Relationship between periodontitis and rheumatoid arthritis and the effect of non-surgical periodontal treatment. Braz Dent J. 2009;20:355-64.

68.• Kaur S, Bright R, Proudman SM, Bartold PM. Does periodontal treatment influence clinical and biochemical measures for rheumatoid arthritis? A systematic review and meta-analysis. Semin Arthritis Rheum. 2014;44:113-122. Meta-analysis assessing the benefit of nonsurgical periodontal treatment in individuals with periodontitis and RA concludes that clinical and laboratory markers of $R A$ disease activity may be improved.

69. Soory M. Periodontal diseases and rheumatoid arthritis: a coincident model for therapeutic intervention? Curr Drug Metab. 2007;8:750-7.

70. Gu Y, Walker C, Ryan ME, Payne JB, Golub LM. Nonantibacterial tetracycline formulations: clinical applications in dentistry and medicine. J Oral Microbiol. 2012; 4. doi: 10.3402/ jom.v4i0.19227.

71. O'Dell JR, Elliott JR, Mallek JA, Mikuls TR, Weaver CA, Glickstein S, et al. Treatment of early seropositive rheumatoid arthritis: doxycycline plus methotrexate versus methotrexate alone. Arthritis Rheum. 2006;54:621-7.

72. Greenwald RA. The road forward: the scientific basis for tetracycline treatment of arthritic disorders. Pharmacol Res. 2011;64: 610-3.

73. Novak MJ, Poison AM, Freeman E. Effects of gold salts on experimental periodontitis I. histometric evaluation of periodontal destruction. J Periodontol. 1984;55:69-77.

74. Poison AM, Novak MJ, Freeman E. Effects of gold salts on experimental periodontitis II. Cell population characteristics. J Periodontol. 1984;55:78-85.

75. Verzeletti GN, Gaio EJ, Rösing CK. Effect of methotrexate on alveolar bone loss in experimental periodontitis in Wistar rats. Acta Odontol Scand. 2007;65:348-51.

76. Mayer Y, Balbir-Gurman A, Machtei EE. Anti-tumor necrosis factor-alpha therapy and periodontal parameters in patients with rheumatoid arthritis. J Periodontol. 2009;80:1414-20.

77. Per JO, Saraux A, Pierre R, Youinou P. Anti-TNF- $\alpha$ immunotherapy is associated with increased gingival inflammation without clinical attachment loss in subjects with rheumatoid arthritis. J Periodontol. 2008;79:1645-51.

78. Kobayashi T, Yokoyama T, Ito S, Kobayashi D, Yamagata A, Okada M, et al. Periodontal and serum protein profiles in patients with rheumatoid arthritis treated with tumor necrosis factor inhibitor adalimumab. J Periodontol. 2014;85:1480-8. 
79.• Kobayashi T, Okada M, Ito S, Kobayashi D, Ishida K, Kojima A, et al. Assessment of interleukin-6 receptor inhibition therapy on periodontal condition in patients with rheumatoid arthritis and chronic periodontitis. J Periodontol. 2014;85:57-67. Inhibition of IL-6, utilizing tocilizumab, may have beneficial effects on both RA and $P D$.

80. Kawai T, Eisen-Lev R, Seki M, Eastcott JW, et al. Requirement of B7 costimulation for Th-1 mediated inflammatory bone resorption in experimental periodontal disease. J Immunol. 2000;164:2102-9.

81. Rosenstein ED, Scher JU, Bretz WA, Weissmann G. Clinical periodontal and microbiologic parameters in patients with rheumatoid arthritis. J Periodontol. 2011;82:1521-3.

82.• de Aquino SG, Abdollahi-Roodsaz S, Koenders MI, van de Loo FA, Pruijn GJ, Marijnissen RJ, et al. Periodontal pathogens directly promote autoimmune experimental arthritis by inducing a TLR2- and IL-1-driven Th17 response. J Immunol. 2014;192: 4103-11. P gingivalis and Prevotella nigrescens had divergent but additive effects on the severity of experimental arthritis, in part mediated through Th17 cells.

83.•• Brusca SB, Abramson SB, Scher JU. Microbiome and mucosal inflammation as extra-articular triggers for rheumatoid arthritis and autoimmunity. Curr Opin Rheumatol. 2014;26:101-7. Mucosal sites exposed to a high bacterial antigens loads, such as the periodontium, lung, and gut, may lead to the breach of tolerance and represent the initial site of autoimmune generation.

84. Klareskog L, Stolt P, Lundberg K, Källberg H, Bengtsson C, Grunewald J, et al. A new model for an etiology of rheumatoid arthritis: smoking may trigger HLA-DR (shared epitope)-restricted immune reactions to autoantigens modified by citrullination. Arthritis Rheum. 2006;54:38-46.

85. Silman AJ, Newman J, MacGregor AJ. Cigarette smoking increases the risk of rheumatoid arthritis. Results from a nationwide study of disease-discordant twins. Arthritis Rheum. 1996;39:732-5.

86. Hendler A, Mulli TK, Hughes FJ, Perrett D, Bombardieri M, Houri-Haddad Y, et al. Involvement of autoimmunity in the pathogenesis of aggressive periodontitis. J Dent Res. 2010;89:138994.

87.• Lappin DF, Apatzidou D, Quirke AM, Oliver-Bell J, Butcher JP, Kinane DF, et al. Influence of periodontal disease, Porphyromonas gingivalis and cigarette smoking on systemic anti-citrullinated peptide antibody titres. J Clin Periodontol. 2013;40:907-15. Elevated ACPA was seen in patients with PD; PD treatment improved ACPA levels.

88. Stolt P, Bengtsson C, Nordmark B, Lindblad S, Lundberg I, Klareskog L, et al. EIRA study group. Quantification of the influence of cigarette smoking on rheumatoid arthritis: results from a population based case-control study, using incident cases. Ann Rheum Dis. 2003;62:835-41.

89. Hutchison D, Moots R. Cigarette smoking and severity of rheumatoid arthritis. Rheumatology (Oxford). 2001;40:1426-7.

90. Heliövaara M, Aho K, Aromaa A, Knekt P, Reunanen A. Smoking and risk of rheumatoid arthritis. J Rheumatol. 1993;20:1830-5.

91. Walker WC. Pulmonary infections and rheumatoid arthritis. Q J Med. 1967;36:239-51.

92.• Quirke AM, Lugli EB, Wegner N, Hamilton BC, Charles P, Chowdhury $\mathrm{M}$, et al. Heightened immune response to autocitrullinated Porphyromonas gingivalis peptidylarginine deiminase: a potential mechanism for breaching immunologic tolerance in rheumatoid arthritis. Ann Rheum Dis. 2013;73:2639. Antibodies to PPAD were found in the serum of RA patients; PPAD can become autocitrullinated, suggesting that a specific immune response to PPAD could lead to the loss of tolerance to citrullinated proteins in $R A$.

93. Demoruelle MK, Weisman MH, Simonian PL, Lynch DA, Sachs PB, Pedraza IF, et al. Airways abnormalities and rheumatoid arthritis-related autoantibodies in subjects without arthritis: early injury or initiating site of autoimmunity? Arthritis Rheum. 2012;64:1756-61.

94. Aceves-Avila FJ, Medina F, Fraga A. The antiquity of rheumatoid arthritis: a reappraisal. J Rheumatol. 2001;28:751-7.

95. Vaahtovuo J, Munukka E, Korkeamäki M, Luukkainen R, Toivanen P. Fecal microbiota in early rheumatoid arthritis. J Rheumatol. 2008;25:1500-5.

96. Liu X, Zou Q, Zeng B, Fang Y, Wei H. Analysis of fecal Lactobacillus community structure in patients with early rheumatoid arthritis. Curr Microbiol. 2013;67:170-6.

97. Kaur S, White S, Bartold PM. Periodontal disease and rheumatoid arthritis: a systematic review. J Dent Res. 2013;92:399-408.

98. Golub LM, Payne JB, Reinhardt RA, Nieman G. Can systemic diseases co-induce (not just exacerbate) periodontitis? A hypothetical "two-hit" model. J Dent Res. 2006;85:102-5.

99. Totaro MC, Cattani P, Ria F, Tolusso B, Gremese E, Fedele AL, et al. Porphyromonas gingivalis and the pathogenesis of rheumatoid arthritis: analysis of various compartments including the synovial tissue. Arthritis Res Ther. 2013;15:R66.

100. Matsuo K, Xiang Y, Nakamura H, Masuko K, Yudoh K, Noyori $\mathrm{K}$, et al. Identification of novel citrullinated autoantigens of synovium in rheumatoid arthritis using a proteomic approach. Arthritis Res Ther. 2006;8:R175.

101.• Kinloch AJ, Alzabin S, Brintnell W, Wilson E, Barra L, Wegner $\mathrm{N}$, et al. Immunization with Porphyromonas gingivalis enolase induces autoimmunity to mammalian alpha-enolase and arthritis in DR4-IE-transgenic mice. Arthritis Rheum. 2011;63:3818-23. Animal model linking the immune response to an enolase of $P$. gingivalis to a human $\alpha$-enolase seen in patinets with $R A$ enolase.

102. Van Steendam K, Tilleman K, De Ceuleneer M, De Keyser F, Elewaut D, Deforce D. Citrullinated vimentin as an important antigen in immune complexes from synovial fluid of rheumatoid arthritis patients with antibodies against citrullinated proteins. Arthritis Res Ther. 2010;12:R132.

103.• Dwivedi N, Radic M. Citrullination of autoantigens implicates NETosis in the induction of autoimmunity. Ann Rheum Dis. 2014;73:483-91. The phagocytic processing of deiminated chromatin together with bacterial adjuvants may induce the presentation of modified histone epitopes that can act as powerful stimuli to break tolerance.

104. Cooper PR, Palmer LJ, Chapple IL. Neutrophil extracellular traps as a new paradigm in innate immunity: friend or foe? Periodontology 2000. 2013;63:165-97.

105. Scinocca M, Bell DA, Racape M, Joseph R, Shaw G, McCormick $\mathrm{JK}$, et al. Antihomocitrullinated fibrinogen antibodies are specific to rheumatoid arthritis and frequently bind citrullinated proteins/ peptides. J Rheumatol. 2014;41:270-9.

106. Jiang X, Trouw LA, van Wesemael TJ, Shi J, Bengtsson C, Källberg $\mathrm{H}$, et al. Anti-CarP antibodies in two large cohorts of patients with rheumatoid arthritis and their relationship to genetic risk factors, cigarette smoking and other autoantibodies. Ann Rheum Dis. 2014;73:1761-8.

107. Mydel P, Wang Z, Brisslert M, Hellvard A, Dahlberg LE, Hazen SL, et al. Carbamylation-dependent activation of T cells: a novel mechanism in the pathogenesis of autoimmune arthritis. J Immunol. 2010;184:6882-90.

108. Kozireva SV, Zestkova JV, Mikazane HJ, Kadisa AL, Kakurina NA, Lejnieks AA, et al. Incidence and clinical significance of parvovirus B19 infection in patients with rheumatoid arthritis. J Rheumatol. 2008;35:1265-70.

109. Bright R, Proudman SM, Rosenstein ED, Bartold PM. Is there a link between carbamylation and citrullination in periodontal disease and rheumatoid arthritis? Medical Hypotheses 2015 [accepted for publication]. 
110. Croia C, Serafini B, Bombardieri M, Kelly S, Humby F, Severa M, et al. Epstein-Barr virus persistence and infection of autoreactive plasma cells in synovial lymphoid structures in rheumatoid arthritis. Ann Rheum Dis. 2013;72:1559-68.

111. Smolen JS, Aletaha D, Bijlsma JW, Breedveld FC, Boumpas D, Burmester G, et al. Treating rheumatoid arthritis to target: recommendations of an international task force. Ann Rheum Dis. 2010;69:631-7.

112. Lahiri M, Morgan C, Symmons DP, Bruce IN. Modifiable risk factors for RA: prevention, better than cure? Rheumatology (Oxford). 2012;51:499-512.

113. Proudman SM, James MJ, Spargo LD, Metcalf RG, Sullivan TR, Rischmueller M, et al. Fish oil in recent onset rheumatoid arthritis: a randomised, double-blind controlled trial within algorithm-based drug use. Ann Rheum Dis. 2015;74:89-95.

114. Reed GW, Leung K, Rossetti RG, Vanbuskirk S, Sharp JT, Zurier RB. Treatment of rheumatoid arthritis with marine and botanical oils: an 18-month, randomized, and double-blind trial. Evid Based Complement Alternat Med. 2014;2014:857456. doi:10.1155/ 2014/857456

115. Rosenstein ED, Kushner LJ, Kramer N, Kazandjian G. Pilot study of dietary fatty acid supplementation in the treatment of adult periodontitis. Prostaglandins Leukot Essent Fat Acids. 2003;68: 213-8.

116. Sculley DV. Periodontal disease: modulation of the inflammatory cascade by dietary n-3 polyunsaturated fatty acids. J Periodontal Res. 2014;49:277-81.
117. de Hair MJ, Landewé RB, van de Sande MG, van Schaardenburg D, van Baarsen LG, Gerlag DM, et al. Smoking and overweight determine the likelihood of developing rheumatoid arthritis. Ann Rheum Dis. 2013;72:1654-8.

118. Fisher MC, Hochberg MC, El-Taha M, Kremer JM, Peng C, Greenberg JD, et al. Smoking, smoking cessation, and disease activity in a large cohort of patients with rheumatoid arthritis. J Rheumatol. 2012;39:904-9.

119. Di Giuseppe D, Orsini N, Alfredsson L, Askling J, Wolk A. Cigarette smoking and smoking cessation in relation to risk of rheumatoid arthritis in women. Arthritis Res Ther. 2013;15:R56.

120. Chambrone L, Preshaw PM, Rosa EF, Heasman PA, Romito GA, Pannuti CM, et al. Effects of smoking cessation on the outcomes of non-surgical periodontal therapy: a systematic review and individual patient data meta-analysis. J Clin Periodontol. 2013;40: 607-15.

121. Sandberg ME, Bengtsson C, Källberg H, Wesley A, Klareskog L, Alfredsson L, et al. Overweight decreases the chance of achieving good response and low disease activity in early rheumatoid arthritis. Ann Rheum Dis. 2014;73:2029-33.

122. Uutela T, Kautiainen H, Järvenpää S, Salomaa S, Hakala M, Häkkinen A. Waist circumference based abdominal obesity may be helpful as a marker for unmet needs in patients with RA. Scand J Rheumatol. 2014;43:279-85.

123. Chaffee BW, Weston SJ. Association between chronic periodontal disease and obesity: a systematic review and meta-analysis. J Periodontol. 2010;81:1708-24. 